\title{
ENSAIO LABORATORIAL E CLÍNICO COM HYCANTHONE NÔVO AGENTE ESQUISTOSSOMICIDA *
}

\author{
Naftale Katz e J. Pellegrino
}

\begin{abstract}
A partir do Miracil D, um derivado hidroximetilico (Hycanthone) pode ser obtido através da atividade biológica do Aspergillus sclerotiorum. Este derivado mostrou-se muito ativo quando administrado a camundongos, hamsters e macacos Cebus experimentalmente infectados com Schistosoma mansoni.

Ensaios clinicos com o Hycanthone foram feitos em 52 pacientes com esquistossomose mansoni ativa. A droga foi administrada, nas doses de 2 e $3 \mathrm{mg} / \mathrm{kg} /$ dia, junto com um anti-ácido, duas vêzes ao dia, durante 5 dias consecutivos. Com exceção de 2 casos, todos os pacientes completaram o tratamento. Náusea e/ou vômito, anorexia, tonturas e cefaléia foram os efeitos colaterais mais comuns. Atividade terapêutica foi avaliada através de repetidos exames de fezes (4 a 6) e uma biópsia retal realizada a partir do $4 .^{\circ}$ mês após o tratamento. As percentagens de cura foram de 83,3 e $80,0 \%$ com o esquema de 2 e $3 \mathrm{mg} / \mathrm{kg}$, respectivamente.

Os dados laboratoriais e clínicos sôbre a atividade esquistossomicida do Hycanthone até agora obtidos mostram a necessidade de novos ensaios com êste promissor medicamento.
\end{abstract}

E bem conhecido o fato de que o Miracil D (Lucanthone ${ }^{R}$ ), um derrvado tioxantônico, passa por diferentes transformações metabólicas em várias espécies de vertebrados e que a sua atividade esquistossomicida está ligada a determinados metabólitos. Muitas tentativas foram feitas com o intuito de se caracterizar e isolar as possíveis frações ativas. Strufe (20), em 1963, demonstrou que os metabólitos eliminados pela urina varian de acôrdo com o hospedeiro tratado. Assim, em camundongos, o metabólito que é eli. minado em maior quantidade é uma sulfona; em macacos, um sulfóxido, e, no homem, um cromopeptide. Recentemente, ficou demonstrado que um derivado hidroximetílico (HYcanthone ${ }^{R}$ ) pode ser obtido do Miracil D, através da atividade biológica de um fungo, o Asperg1llus sclerotiorum. Este composto mostrou gran- de atividade quando administrado por via oral ou intraperitoneal a hamsters axperimentalmente infectados com Schistosoma mansoni e foi considerado o metabólito ativo do Miracil D $(2,18)$.

Este trabalho apresenta os resultados até agora obtidos com o Hycanthone (Sterling-Winthrop) em camundongos, hamsters e macacos Cebus experimentalmente infectados, bem como em pacientes com esquistossomose mansoni ativa. Nêle foram incluídos dados publicados (15) ou em publicação (7) sôbre o mesmo agente esquistossomicida.

\section{MATERIAL E METODOS}

Infecção dos animais

Foram utilizadas cercárias eliminadas por Biomphalaria glabrata infectada no la- 
QUADRO 1 - Atividade terapêutica do Hycanthone em camundongos experimentalmente infectados com Schistoscma mansoni. Alteraçoes do ooerama, distribuição dos esquistossomos e percentacem de vermes mortos no fígado.

\begin{tabular}{|c|c|c|c|c|c|c|c|c|}
\hline \multirow{2}{*}{$\begin{array}{c}\text { Esquema de } \\
\text { tratamento } \\
\text { com } \\
\text { Hycanthone } \\
\text { (mg/kg/dia } \times 7 \\
\text { per os) }\end{array}$} & \multirow{2}{*}{$\begin{array}{l}\text { Número } \\
\text { de } \\
\text { Animaio }\end{array}$} & \multirow{2}{*}{$\begin{array}{l}\text { Animais } \\
\text { mortos }\end{array}$} & \multirow{2}{*}{$\begin{array}{l}\text { Média } \\
\text { de } \\
\text { vermes }\end{array}$} & \multirow{2}{*}{$\begin{array}{l}\text { Percentagem } \\
\text { de vermes } \\
\text { mortos no } \\
\text { fígado }\end{array}$} & \multicolumn{3}{|c|}{$\begin{array}{l}\text { Distribuição de } \\
\text { esquistossomos }(\%)\end{array}$} & \multirow{2}{*}{$\begin{array}{l}\text { Percent,agem } \\
\text { de animais } \\
\text { com } \\
\text { alteraçöes } \\
\text { no oo erama }\end{array}$} \\
\hline & & & & & Fícado & Porta & Mesentério & \\
\hline 80 & 12 & 4 & 13,2 & 48,8 & 98,1 & 0,0 & 1,9 & 100,0 \\
\hline 10 & 12 & 4 & 22,5 & 27,7 & 93,3 & 2,8 & 3,9 & 62,5 \\
\hline 20 & 12 & 6 & 26,1 & 4,4 & 63,7 & 10,2 & 26,1 & 16,7 \\
\hline 10 & 12 & 4 & 27,0 & 1,3 & 40,8 & 22,2 & 37,0 & 12,5 \\
\hline Contrôle & 12 & 3 & 22,1 & 0,0 & 19,5 & 44,2 & 36,3 & 0,0 \\
\hline
\end{tabular}


boratório (amostra L. E.). Camundongos, cujo pêso variou de 18 a $20 \mathrm{gr}$, foram expostos a $100 \pm 10$ cercárias pelo método de imersão da cauda (9). Hamters adultos (Cricetus auratus) foram infectados com $60 \pm 10$ cercárias através da bolsa alimentar (14). A via transcutânea fò̀ utilizada para infecção de Cebus apella. macrocephalus Spix, 1823, com $150 \pm 20$ cercárias.

\section{Tratamento dos animais infectados}

Camundongos: após 10 semanas da exposição, grupos de 12 animais foram tratados com Hycanthone, per os, durante 7 dias consecutivos, com doses de 80 , 40,20 e $10 \mathrm{mg} / \mathrm{kg}$. Outro grupo de 12 animais não foi tratado, servindo como contrôle (Quadro 1).

Hamsters : grupos de 6 animais foram tratados por 7 dias consecutivos per as, com doses de $8,4,2$ e $1 \mathrm{mg} / \mathrm{kg}, 8$ semanas após a infecção com cercárias de S. mansoni. Outro grupo de 6 animais, não tratados, serviu como contrôle (Quadro 2).

Macacos: 5 Cebus foram tratados com Hycanthone, 4 a 7 meses após a infecção, com doses diárias de $10 \mathrm{mg} / \mathrm{kg}$ ( 1 animal), $5 \mathrm{mg} / \mathrm{kg}$ (2 animais) e 2,5 $\mathrm{mg} / \mathrm{kg}$ (2 animais), durante 5 dias consecutivos. Um anti-ácido $\left(\right.$ Pepsamar $^{\mathrm{R}}$ Gel) foi administrado ao Cebus A-13 e A-22, na dose de $100 \mathrm{mg} / \mathrm{kg} / \mathrm{dia}$. Dois macacos não tratados foram deixados como contrôle (Quadro 3).

Oograma e distribuição dos esquistossomos

Camundongos e hamsters foran! sacrificados com pancada na nuca, 3 dias após o término do tratamento .

Os esquistossomos localizados nas veias mesentéricas, porta e fígado foram recuperados por perfusão, usando a técnica de Pellegrino \& Siqueira (10), adaptada a camundongos e hamsters. O estudo do oograma foi feito em fragmentos retirados do intestino, comprimidos entre iâmina e lamínula e examinados microscòpicamente (12). Duzentos ovos viáveis eram contados e classificados de acôrdo com critérios prèviamente descritos $(11,16)$ 1 ? estádio, embrião ocupando cêrca de $1 / 3$ do diâmetro transversal do ôvo; $2^{\circ}$ está. dio, embrião com tamanho aproximadamente igual ao diâmetro transversal; $3^{\circ}$ estádio, $2 / 3$ do diâmetro longitudinal do ôvo; 4 ' estádio, o embrião ocupa pràticamente tôda a superfície interna do ôvo. Os ovos maduros contêm um miracídic completamente desenvolvido. Fragmentos retais (geralmente 4) de macacos $\mathrm{Ce}$ bus foram retirados por curetagem da mu. cosa (13), sendo os fragmentos examina. dos e todos elementos esquistossomóticos contados e classificados.

Alterações do oograma, em fragmentos intestinais de camundongos e hamsters. foram consideradas significativas quando um ou mais estádios, correspondentes a ovos imaturos, estavam ausentes. Em macacos Cebus, a avaliação da atividade terapêutica foi baseada no desaparecimento gradual dos ovos imaturos e maduros nos fragmentos retais.

Em camundongos e hamsters, o número de vermes mortos no fígado foi rotineiramente determinado após o esmagamento completo dêste órgão entre duas placas de vidro e o exame feito com mi. croscópio de dissecção.

\section{Seleção dos pacientes com esquistossomose e esquema terapêutico}

Dois grupos de pacientes com esquistossomose mansoni ativa foram incluídos no presente trabalho. Os pacientes do $1^{\circ}$ grupo (27 casos) foram tratados com Hycanthone na dose de $2 \mathrm{mg} / \mathrm{kg}$, duas vêzes por dia, durante 5 dias consecutivos (Grupo A). A droga foi administrada por via oral, em forma de cápsulas contendo $25 \mathrm{mg}$, simultâneamente com $15 \mathrm{ml}$ de um preparado anti-ácido $\left(\right.$ Pepsamar $\left.^{\mathrm{R}}-\mathrm{Gel}\right)$. Estes pacientes foram selecionados entre aquêles que espontâneamente procuravam o ambulatório do Hospital da Cruz Vermelha, Belo Horizonte, para tratamento médico. Os seguintes exames complementares foram feitos antes e várias vêzes após - tratamento: hemograma, sumário de urina, testes de função hepática (turva- 
QDADRO 2 - Atividade terapêtica do Hycanthone hamsters experimentalmente infectados com Schistogoma mansoni. Alteraçöes do oograma, distribuição dos osquistossomos e vermes mortos no fígado.

\begin{tabular}{|c|c|c|c|c|c|c|c|c|}
\hline \multirow{2}{*}{$\begin{array}{c}\text { Esquema de } \\
\text { tratamento } \\
\text { com } \\
\text { Hycanthone } \\
(\mathrm{mg} / \mathrm{kg} / \mathrm{dia} \times 7 \\
\text { per og })\end{array}$} & \multirow{2}{*}{$\begin{array}{c}\text { Numero } \\
\text { de } \\
\text { hamsters }\end{array}$} & \multirow{2}{*}{$\begin{array}{l}\text { Animalo } \\
\text { mortos }\end{array}$} & \multirow{2}{*}{$\begin{array}{c}\text { Média } \\
\text { de } \\
\text { Vermer }\end{array}$} & \multirow{2}{*}{$\begin{array}{l}\text { Percentagem } \\
\text { de vermes } \\
\text { mortos no } \\
\text { fígado }\end{array}$} & \multicolumn{3}{|c|}{$\begin{array}{l}\text { Distribuição do } \\
\text { osquistossomos (\%) }\end{array}$} & \multirow{2}{*}{$\begin{array}{l}\text { Percentagem } \\
\text { de animais } \\
\text { com } \\
\text { alteraf̧ös } \\
\text { no oograma }\end{array}$} \\
\hline & & & & & Fígado & Porta & Mesentério & \\
\hline 8 & 6 & 0 & 20,3 & 61,5 & 88,2 & 6,9 & 4,9 & 100,0 \\
\hline 4 & 6 & 2 & 7,0 & 10,7 & 64,4 & 27,8 & 17,8 & 75,0 \\
\hline 2 & 6 & 1 & 21,8 & 0,0 & 43,2 & 18,3 & 38,5 & 20,0 \\
\hline 1 & 6 & 1 & 19,0 & 0,0 & 16,7 & 45,4 & 37,9 & 0,0 \\
\hline Contrôlo & 6 & 0 & 26,1 & 00 & 15,3 & 27,9 & 56,8 & 0,0 \\
\hline
\end{tabular}


ção do timol, bilirrubina e transaminases séricas) e eletrocardiograma.

Os pacientes do $2^{\circ}$ grupo (25 casos) foram selecionados entre militares da ativa, aparentando bom estado de saúde (Grupo B). O Hycanthone foi administrado como no Grupo A, sendo a dose de $3 \mathrm{mg} / \mathrm{kg}$.

Os grupos etários, sexo, côr e formas clínicas encontram-se no Quadro 4.

\section{Critérios de avaliaçãs da atividade terapêutica}

A avaliação da atividade quimiote. rápica foi feita em duas etapas: a) contrôle inicial e b) contrôle tardio. No contrôle inicial, foi feita uma biópsia retal ( 6 a 8 fragmentos retirados das válvulas de Houston), no primeiro mês após o tratamento. A ausência de ovos imaturos viáveis nos fragmentos retirados foi interpretada como evidência de interrupção da postura $(4,16)$. O contrôle tardio foi baseado nos dados obtidos através de 4 a 6 exames de fezes (3) e uma biópsia retal praticada, após o tratamento, do $4^{\circ}$ mês em diante. Os pacientes foram considerados como provàvelmente curados quando não eram encontrados ovos viáveis nos exames de fezes ou nos fragmentos das biópsias retais.

\section{RESULTADOS}

Os resultados obtidos em camundongos experimentalmente infectados coms. mansoni e tratados com Hycanthone po dem ser vistos no Quadro 1. Deslocamento dos esquistossomos para o fígado foi observado em todos os esquemas de tratamento utilizados, chegando a $90 \%$ com a dose diária de 80 e $40 \mathrm{mg} / \mathrm{kg}$. O oograma de todos os camundongos tratados com 80 $\mathrm{mg} / \mathrm{kg}$ estava alterado. Um decréscimo progressivo na percentagem de camundongos com alterações do oograma foi observado com as doses de $40 \mathrm{mg} / \mathrm{kg}(62,5 \%)$, $20 \mathrm{mg} / \mathrm{kg}(16,7 \%)$ e $10 \mathrm{mg} / \mathrm{kg}(12,5 \%)$

Em hamsters (Quadro 2), a atividade esquistossomicida do Hycanthone foi mais pronunciada. O oograma de todos us animais tratados com $8 \mathrm{mg} / \mathrm{kg}$, durante 7 dias consecutivos, foi encontrado alterado. A percentagem dos animais que apresentaram alterações do oograma foi de 75,0 e $20,0 \%$ nos grupos de hamsters tratados com 4 e $2 \mathrm{mg} / \mathrm{kg}$, respectivamente. Acentuado deslocamento dos vermes para o fígado foi observado nos animais tratados com 8,4 e $2 \mathrm{mg} / \mathrm{kg}$. Não se detectou atividade terapêutica nos animais tratados com $1 \mathrm{mg} / \mathrm{kg}$. $\mathrm{Na}$ dose de $8 \mathrm{mg} / \mathrm{kg}$., durante 7 dias consecutivos, $61,5 \%$ dos esquistossomos foram encontrados mortos no fígado.

Cura parasitólogica foi obtida nos Cebus A-9 e 122, tratados com Hycanthone, per os, durante 5 dias consecutivos, com as doses de 10 e $5 \mathrm{mg} / \mathrm{kg}$ dia respectivamente (Quadro 3). Estes animais foram sacrificados respectivamente 25 e 16 semanas após o término do tratamento. Não foram encontrados vermes vivos e apenas poucos ovos mortos e cascas foram vistos em preparações do fígado e intestino. Interrupção temporária da postura foi detectada no Cebus A-13, tratado com $5 \mathrm{mg} / \mathrm{kg}$ por dia, simultâneamente coır. Pepsamar, durante $\mathbf{5}$ dias consecutivos (Quadro 3). Não houve atividade terapêutica, que pudesse ser evidenciada pelo oograma, nos macacos A-21 e A-22, tratados com 2,5 mg/kg por dia (Quadro3).

Os efeitos colaterais observados nos pacientes tratados com Hycanthone podem ser computados no Quadro 5. A maioria dos sinais e sintomas estavam ligados ao aparêlho gastro-intestinal. Em dois pacientes do Grupo B o tratamento foi interrompido no $2^{\circ}$ e $4^{\circ}$ dias, respectivamente, devido ao aparecimento de vômitos freqüientes e severos.

Outras manifestações colaterais foram de menor significado clínico e não mereceram cuidados especiais. Como pode ser visto no Quadro 5, a intolerância ao Hycanthone foi mais frequiente e pronunciada nos pacientes do Grupo A.

Os dados obtidos através dos exames complementares podem ser assim resumidos:

Hemogramas: eosinofilia e leucocito se, 3 semanas após o término do tratamen to, em 7 de 15 pacientes.

Testes de função hepática: aumenio das transaminases séricas (pirúvica $e$ oxalacética) e turvação do timol, na primeira semana após o tratamento, em 2 e 1 pacientes, respectivamente, de 20 casos examinados.

Sumário de urinas: traços de proteinú. ria, uma semana após o tratamento, em 4 de 26 casos controlados. 
Eletrocardiogeama: discreto achatamento do segmento ST e da onda $T$ em 13 de 23 casos, de 1 a 4 semanas após a terapêutica.

A repressão dos sintomas clínicos devidos à infecção esquistossomótica foi mu to satisfatória. Poucas semanas após o tratamento, pràticamente todos os pacientes apresentaram grande melhora quanto aos seguintes sintomas: diarréia com estrias sanguinolentas, constipaçāo, dôr abdominal, empachamento pós-prandial, etc. Um paciente, com profusa e freqüente enterorragia, melhorou dramàticamente após a administração do Hycanthone.

A interrupção da postura não foi detectada quando se realizou o biópsia retal uma semana após o tratamento (2 pacientes). No entanto, ovos imaturos viáveis não foram encontrados na biósia retal em 17 de 20 pacientes quando esta foi feita 2 a 4 semanas após o tratamento. $A$ atividade terapêutica do Hycanthone (contrôle tardio) foi aproximadamente a mesma nos grupos A e B $\mathbf{( 8 3 , 3}$ e $\mathbf{8 0 , 0} \%$ dos pacientes, respectivamente, foram considerados curados, Quadro 6).

\section{DISCUSSÃO}

A estrutura química do Hycanthone está representada na Figura 1 , sendo $R=$ $\mathrm{CH}^{2} \mathrm{OH}, \mathrm{Y}=\mathrm{S}$ e $\mathrm{X}=\mathrm{H}$. O Hycanthone representa a maior fração metabólica quando o Miracil D (Fig. 1, $\mathbf{R}=\mathrm{CH}^{3}, \mathrm{Y}=\mathrm{S}$, $\mathrm{X}=\mathrm{H}$ ) é biològicamente convertido pelo Aspergillus sclerotiorum numa mistura de novos compostos. De acôrdo com Rosi \& Cols. (18), o Hycanthone é extremsmente sensivel aos ácidos. Quando exposto à ação de ácidos minerais é transformado numa substância neutra, solúvel em água, o que explica a sua não indentificação por investigadores que se ocuparam do problema anteriormente (18).

Trabalhos realizados nos Laboratórios do Sterling-Winthrop Research Institute, Rensselaer, New Yory (19) sôbre a atividade esquissotomicida do Hycanthone, demonstraram que os valores do $\mathrm{ED}^{\text {" }}$ para camundongos e hamsters experimentalmente infectados foram de 15,3 $\pm 2,5$ $\mathrm{mg} / \mathrm{kg} / \mathrm{dia} \times 5$ e de $0,74 \pm 0,22 \mathrm{mg} / \mathrm{kg}$ /dia $\times 5$, respectivamente. Êstes achados indicam que o Hycanthone é três vêzes mais ativo que o Miracil $D$ em camundongos e 10 vêzes mais em hamsters. Nos-

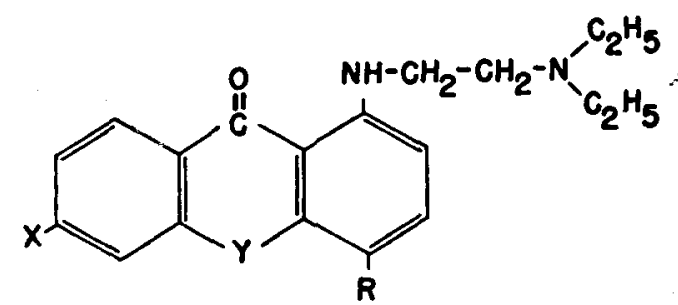

Estrutura química do Hycanthone

sos achados também concordam que a atividade esquissotomicida do Hycanthone é mais pronunciada no hamster do que no camundongo (aproximadamente 10 vêzes.) De acôrdo com a relação estrutura-atividade estabelecida por Berberian 86 Freele (1), o Hycanthone deveria ter acentuada ação esquistossomicida no homem.

A atividade esquistossomicida do $\mathrm{Hy}$ canthone em macacos. Cebus experimentalmente infectados foi muito pronunciada. De fato, não foram encontrados esquistossomos nos macacos 122 e A-9, tratados com as doses de 5 e $10 \mathrm{mg} / \mathrm{kg}$./dia x 5 , respectivamente. Sòmente poucas cascas e ovos mortos foram encontrados em preparação dos fragmentos do intestino e do fígado em. ambos os animais, apesar de uma recidiva transitória observada no Cebus A-9 entre as $10^{\mathrm{a}}$ e $15^{\mathrm{a}}$ semanas após tratamento. $O$ Pepsamar foi administrado aos Cebus A-13 e A-22 na tentativa de aumentar a absorção do produto ativo pela neutralização da acidez gástrica. Os resultados, todavia, foram desapontadores. E interessante salientar que os macacos usados como contrôle (A-15 e 112) apresentaram oograma normal em fragmentos retais retirados, respectivamente, 356 e 277 dias após a infecçăo. Êstes achados realçam o valor do macaco Cebus para ensaios pré-clínicos na esquistossomose mansoni.

Após êstes estudos pré-clínicos, passamos ao ensaio do Hycanthone em pacientes com esquistossomose ativa. Os resultados obtidos, sejam clínicos ou parasitoiógicos, podem ser considerados como altamente satisfatórios. Os efeitos colaterais foram de pouca intensidade, com exceção daqueles ligados ao aparêlho gastro-intestinal. Tentativas para prevenir tais efe tos deverão ser ensaidas (outros esquemas, novas formulações da droga, medicaçăo 


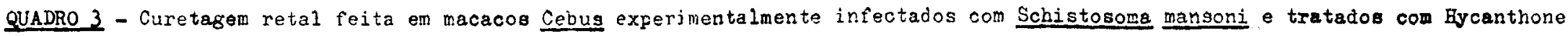

\begin{tabular}{|c|c|c|c|c|c|c|c|c|c|c|c|}
\hline \multirow{2}{*}{ Macaco } & \multirow{2}{*}{$\begin{array}{l}\text { Tsquema de } \\
\text { tratamento com } \\
\text { Hjoanthone }\end{array}$} & \multirow{2}{*}{$\begin{array}{l}\text { Duraşäo de } \\
\text { infecçao quando } \\
\text { o tratamento } \\
\text { foi iniciado }\end{array}$} & \multirow{2}{*}{$\begin{array}{l}\text { Dias antes (-) } \\
\text { do inílo ou } \\
\text { após (+) o } \\
\text { termino do } \\
\text { tratamento }\end{array}$} & \multicolumn{4}{|c|}{ Ovos viáveis. } & \multicolumn{2}{|c|}{ Estáds os } & \multirow{2}{*}{$\begin{array}{c}\text { Ovos } \\
\text { mortos } \\
0 \\
\operatorname{coscas}\end{array}$} & \multirow{2}{*}{$\begin{array}{c}\text { Total de } \\
\text { elementos } \\
\text { esquistossomóticos }\end{array}$} \\
\hline & & & & 10 & $2 *$ & $3 \bullet$ & $4^{\circ}$ & Maduros & Total & & \\
\hline$\Delta-9$ & $\begin{array}{l}10 \mathrm{mg} / \mathrm{kg} / \mathrm{dia}, \\
\text { per og, durante } \\
5 \text { dias conse- } \\
\text { cutivos }\end{array}$ & 5 mêses & $\begin{array}{r}-\quad 7 \\
+\quad 7 \\
+\quad 21 \\
+\quad 35 \\
+\quad 49 \\
+\quad 56 \\
+\quad 70 \\
+\quad 91 \\
+105 \\
+126 \\
+154\end{array}$ & $\begin{array}{l}3 \\
0 \\
0 \\
0 \\
0 \\
0 \\
0 \\
2 \\
3 \\
0 \\
0\end{array}$ & $\begin{array}{c}1 \\
0 \\
0 \\
0 \\
0 \\
0 \\
0 \\
11 \\
0 \\
0 \\
0\end{array}$ & $\begin{array}{l}6 \\
0 \\
0 \\
0 \\
0 \\
0 \\
0 \\
8 \\
1 \\
0 \\
0\end{array}$ & $\begin{array}{l}3 \\
0 \\
0 \\
0 \\
0 \\
0 \\
7 \\
0 \\
3 \\
0 \\
0\end{array}$ & $\begin{array}{c}14 \\
2 \\
0 \\
0 \\
0 \\
0 \\
3 \\
7 \\
24 \\
0 \\
0\end{array}$ & $\begin{array}{c}27 \\
2 \\
0 \\
0 \\
0 \\
0 \\
10 \\
28 \\
31 \\
0 \\
0\end{array}$ & $\begin{array}{l}4 \\
3 \\
2 \\
0 \\
3 \\
7 \\
0 \\
5 \\
3 \\
0 \\
0\end{array}$ & $\begin{array}{r}31 \\
5 \\
2 \\
0 \\
3 \\
7 \\
10 \\
33 \\
34 \\
0 \\
0\end{array}$ \\
\hline 122 & $\begin{array}{l}5 \mathrm{mg} / \mathrm{kg} / \mathrm{d} 1 \mathrm{a} . \\
\frac{\text { per }}{5} \text { dig, durante } \\
\text { cut1voe }\end{array}$ & 5 mèses & $\begin{array}{l}-\quad 1 \\
+\quad 5 \\
+\quad 21 \\
+\quad 35 \\
+\quad 56 \\
+\quad 77 \\
+\quad 91 \\
+105\end{array}$ & $\begin{array}{l}4 \\
5 \\
0 \\
0 \\
0 \\
0 \\
0 \\
0\end{array}$ & $\begin{array}{c}1 \\
11 \\
0 \\
0 \\
0 \\
0 \\
0 \\
0\end{array}$ & $\begin{array}{c}30 \\
10 \\
0 \\
0 \\
0 \\
0 \\
0 \\
0\end{array}$ & $\begin{array}{l}0 \\
0 \\
0 \\
0 \\
0 \\
0 \\
0 \\
0\end{array}$ & $\begin{array}{l}29 \\
12 \\
0 \\
0 \\
0 \\
0 \\
0 \\
0\end{array}$ & $\begin{array}{c}64 \\
38 \\
0 \\
0 \\
0 \\
0 \\
0 \\
0\end{array}$ & $\begin{array}{c}0 \\
14 \\
0 \\
0 \\
0 \\
0 \\
0 \\
0\end{array}$ & $\begin{array}{r}64 \\
52 \\
0 \\
0 \\
0 \\
0 \\
0 \\
0\end{array}$ \\
\hline$A-13$ & $\begin{array}{c}5 \mathrm{mg} / \mathrm{lug} / \mathrm{dia}, \\
+ \text { Pepsenar } \\
\text { pez og, durante } \\
5 \text { diss conso- } \\
\text { cut1vos }\end{array}$ & 7 mêses & $\begin{array}{r}-\quad 6 \\
+\quad 5 \\
+\quad 12 \\
+\quad 21 \\
+\quad 28 \\
+\quad 56 \\
+\quad 77 \\
+\quad 84\end{array}$ & $\begin{array}{c}6 \\
10 \\
0 \\
0 \\
0 \\
0 \\
0 \\
0\end{array}$ & $\begin{array}{l}6 \\
0 \\
0 \\
0 \\
0 \\
0 \\
0 \\
0\end{array}$ & $\begin{array}{c}58 \\
3 \\
\cdot 0 \\
0 \\
0 \\
0 \\
0 \\
2\end{array}$ & $\begin{array}{c}2 \\
10 \\
0 \\
0 \\
0 \\
0 \\
2 \\
0\end{array}$ & $\begin{array}{c}20 \\
16 \\
3 \\
0 \\
1 \\
0 \\
13 \\
4\end{array}$ & $\begin{array}{c}92 \\
39 \\
3 \\
0 \\
2 \\
0 \\
15 \\
6\end{array}$ & $\begin{array}{c}23 \\
113 \\
9 \\
0 \\
4 \\
0 \\
6 \\
0\end{array}$ & $\begin{array}{r}115 \\
152 \\
3 \\
0 \\
5 \\
0 \\
21 \\
6\end{array}$ \\
\hline
\end{tabular}


3ULRO 3 - Contimuação

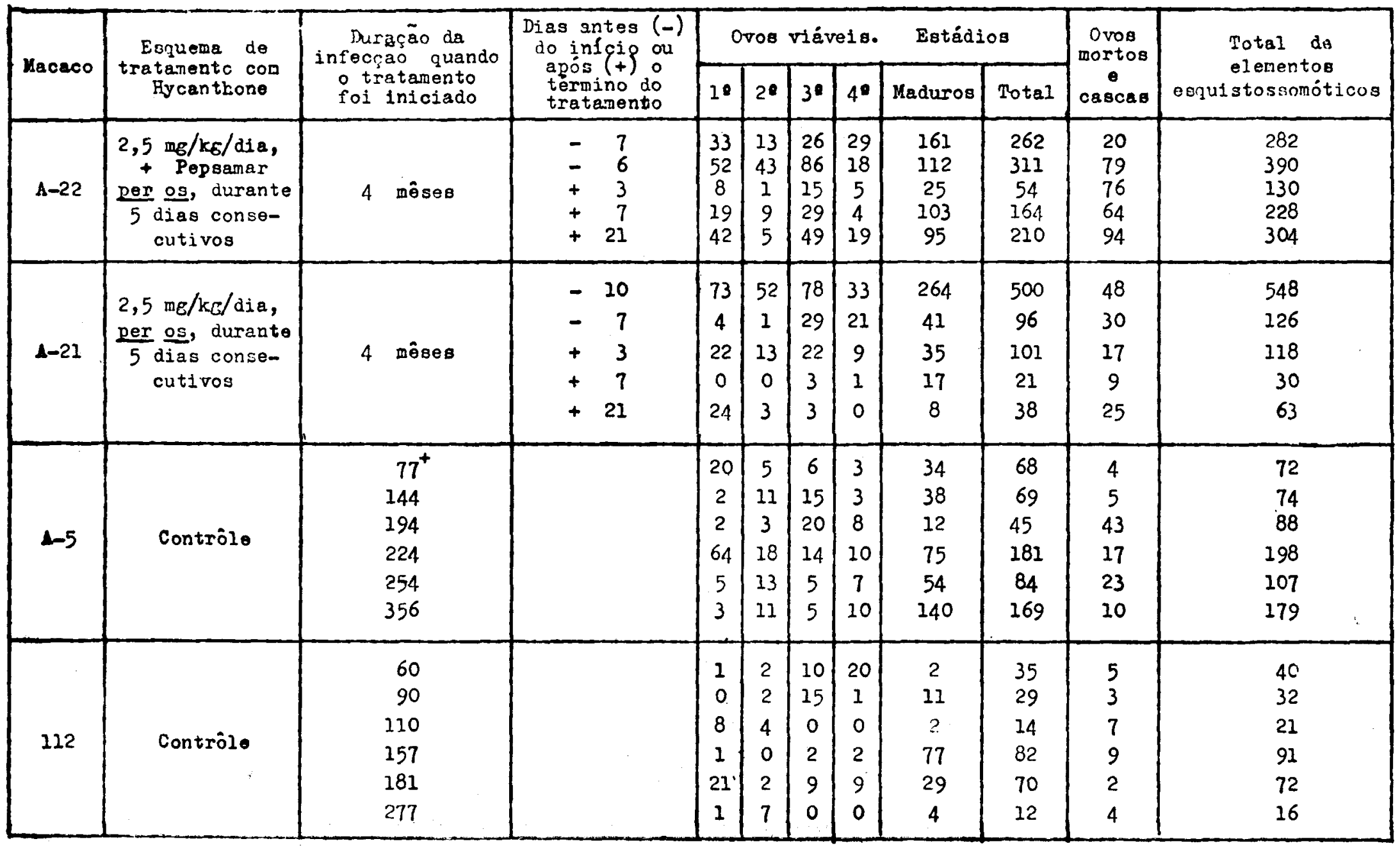

+ Dias após exposição a cercárias de S. mansont 
QUADRO 4 - Datribuição quanto a Erapo etário, sexo, cór - formas clínicas nos Grupos A B

\begin{tabular}{|c|c|c|c|}
\hline & Grupos & Grupo $A$ & Grupo B \\
\hline Esquema & do tratamento & $2 \mathrm{mg} / \mathrm{kg} / \mathrm{dia} \times 5$ & $3 \mathrm{mg} / \mathrm{kg} / \mathrm{dia} \times 5$ \\
\hline Número & do pacientes & 27 & 25 \\
\hline Grupo etário & $\begin{array}{l}\text { Crianças } \\
\text { (11-15 anos) } \\
\text { Adultos } \\
\text { (16-37 anos) }\end{array}$ & $\begin{array}{l}11 \\
16\end{array}$ & $\begin{array}{c}0 \\
25\end{array}$ \\
\hline Sexo & $\begin{array}{l}\text { Masculino, } \\
\text { Feminino }\end{array}$ & $\begin{array}{l}15 \\
12\end{array}$ & $\begin{array}{l}25 \\
0\end{array}$ \\
\hline Côs & $\begin{array}{l}\text { Branca } \\
\text { Preta } \\
\text { Parda }\end{array}$ & $\begin{array}{c}15 \\
3 \\
9\end{array}$ & $\begin{array}{l}8 \\
6 \\
11\end{array}$ \\
\hline Forma clínica & $\begin{array}{l}\text { Hépato-intestinal } \\
\text { Hépato-esplênica }\end{array}$ & $\begin{array}{l}25 \\
2\end{array}$ & $\begin{array}{l}25 \\
0\end{array}$ \\
\hline
\end{tabular}

sintomática). Saliente-se que manifestações psiconeurológicas, tais como convulsões, observadas durante a administração do Miracil D (17), não ocorreram no presente ensaio. Como pode ser visto no Quadro 5, manifestações colaterais foram freqüentes e pronunciadas no Grupo $A$, apesar da menor dosagem utilizada $(2 \mathrm{mg} / \mathrm{kg}$ ). Esta aparente discrepância pode ser em parte explicada se considerarmos que os pacientes do Grupo A procuravam espontâneamente cuidados médicos e eram portadores de associações mórbidas, enquanto que os do grupo $B$ apresentavam boa saúde.

As alterações das provas de função hepática e a presença de proteinúria obser. vadas em alguns pacientes, bem com. discretas alterações do traçado eletrocar- diográfico, podem ser consideradas como de origem tóxica mas foram de significado limitado do ponto de vista clínico. Alterações transitórias do traçado eletrocardiográfico podem ocorrer com outros agentes esquistossomicidas atualmente em uso (5, $6,8)$.

Como outros derivados tioxantônicos, - Hycanthone atua de modo relativamente lento. De fato, no grupo estudado, a interrupção da postura iniciou-se, aparentemente, a partir da $2^{\alpha}$ semana após a terapêutica.

Recidiva parasitológica temporária foi observada em dois pacientes no segundo mês após o tratamento, pois foram encontrados ovos maduros nas fezes. Exames de fezes seriados e uma bióspia retal, realizados 3 e 4 meses após, não mais revela- 
QUADRO 5 - Efeitos colaterats observados durante o tratamento com Hycanthone em 52 pacientes

\begin{tabular}{|c|c|c|c|c|c|c|c|c|c|c|}
\hline & \multicolumn{6}{|c|}{ GRUPO A (27 casos) } & \multicolumn{4}{|c|}{ GRUPO B (25 casos) } \\
\hline EFEITOS COLATERAIS & $\begin{array}{l}0 \\
0 \\
9 \\
9\end{array}$ & $\begin{array}{l}0 \\
0 \\
0 \\
0 \\
0 \\
0 \\
0 \\
0\end{array}$ & 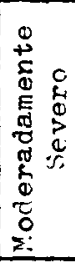 & $\begin{array}{l}0 \\
0 \\
6 \\
0 \\
0 \\
0 \\
0\end{array}$ & $\begin{array}{c}\text { Total } \\
e \\
(c, p)\end{array}$ & 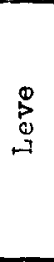 & 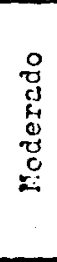 & 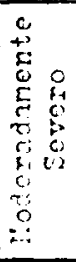 & 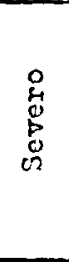 & $\begin{array}{c}\text { Total } \\
e \\
\left(c^{\prime}\right)\end{array}$ \\
\hline Anorexia & 0 & 4 & 4 & 2 & $10(37,0)$ & 1 & 1 & 0 & 1 & $3(12,0)$ \\
\hline Náusea & 3 & 5 & 3 & 1 & $12(44,4)$ & 6 & 6 & 0. & $\cdot 2^{+}$ & $14(56,0)$ \\
\hline Vômito & 5 & 4 & 4 & 0 & $13(48,1)$ & 3 & 5 & 0 & $2^{+}$ & $.10(40,0)$ \\
\hline Cólica & 0 & 6 & 0 & 0 & $6(22,2)$ & 0 & 0 & 0 & 0 & $0(0,0)$ \\
\hline Constipaçäo & 0 & 1 & 3 & 0 & $4(14,8)$ & 0 & 0 & 0 & 0 & $0(0,0)$ \\
\hline Sialorréia & 0 & 0 & 1 & 0 & $1(3,7)$ & 0 & 0 & 0 & 0 & $0(0,0)$ \\
\hline Cefaléia & 5 & 0 & 1 & 0 & $6(22,2)$ & 1 & 1 & 0 & 0 & $2(8,0)$ \\
\hline Tontura & 3 & 3 & 0 & 0 & $6(22,2)$ & 1 & 2 & 0 & 0 & $3(12,0)$ \\
\hline Insônia & 2 & 0 & 0 & 0 & $2(7,4)$ & 0 & 0 & 0 & 0 & $0(0,0)$ \\
\hline Parestesia & 0 & 1 & 0 & 0 & $1(3,7)$ & 0 & 0 & 0 & 0 & $0(0,0)$ \\
\hline Mialgia & 3 & 1 & 0 & 0 & $4(14,8)$ & 0 & 1 & 0 & 0 & $1(4,0)$ \\
\hline Astenia & 0 & 3 & 1 & 0 & $4(1<, 8)$ & 0 & 1 & 0 & 0 & $I(4,0)$ \\
\hline Prurido & 0 & 1 & 0 & 0 & $1(3,7)$ & 0 & 0 & 0 & 0 & $0(0,0)$ \\
\hline Lacrime jamento & 0 & 1 & 0 & 0 & $1(3,7)$ & 0 & 0 & 0 & 0 & $0(0,0)$ \\
\hline Tanuicardia & 4 & 0 & 0 & 0 & $4(14,8)$ & IִC & NC & NC & $\mathrm{HC}$ & \\
\hline Perda de pêso $>1 \mathrm{~kg}$ & 4 & 0 & 0 & 0 & $4(1,4,8)$ & NC & NC & NC & ISC & \\
\hline Sem efeitos colaterajs & & & & & $9(33,3)$ & & & & - & $9(36,0)$ \\
\hline
\end{tabular}

+ Tratamento foi suspenso

NC - Não controlado 


\section{QUADRO 6 - Contrôle da atividade terapêtioa do Hycantbone} em 24 pacientes do Grupo A e 20 pacientes do Grupo B

\begin{tabular}{|c|c|c|c|c|}
\hline \multirow{2}{*}{ Grupos } & \multirow{2}{*}{$\begin{array}{l}\text { Contrôle inicial } \\
\text { (biópsia retal) }\end{array}$} & \multicolumn{3}{|c|}{ Contrôle tardio } \\
\hline & & $\begin{array}{l}\text { Biópsia } \\
\text { retal }\end{array}$ & $\begin{array}{l}\text { Eyame das } \\
\text { fezes }\end{array}$ & $\begin{array}{c}\text { Pacientes considerados } \\
\text { curados/Total }\end{array}$ \\
\hline$A$ & $5 / 22^{+}$ & $2 / 16^{+}$ & $3 / 20^{++}$ & $20 / 24$ \\
\hline B & $\mathrm{MF}$ & $3 / 7$ & $1 / 17$ & $16 / 20$ \\
\hline
\end{tabular}

+ Pacientes com ovos viáveis imaturos no fracmento retal / total de casos examinados

++ Casps com ovos viáveis / total de casos examinados

WF - Não feito.

ram ovos viáveis. Aliás, achados semelhantes foram observados no Cebus A-13.

No presente ensaio, um anti-ácido foi simultâneamente administrado ao Hycantone para prevenir possiveis alterações da droga pelo suco gástrico. Ensaios com cápsulas de desintegração entérica e com fo:- mulação parenteral do Hycanthone já estão em andamento.

Os dados laboratoriais e clínicos sóbre a atividade esquistossomicida do $\mathrm{Hy}$ canthone até agora obtidos, mostram a necessidade de novos ensaios com êste pro. missor medicamento.

\section{SUMMARY}

Starting from Miracil $D$ (Lucanthone), a hydroxymethyl derivative (Hycanthone) can be obtained through the biological activity of the microorganism Aspergillus sclerotiorum. This compound was claimed to be the antischistosomal metabolite of Miracil $D$ and was found very active when administered to mice, hamsters and Cebus monkeys experimentally infected with Schistosoma mansoni.

Clinical trials with Hycanthone were performed on 52 patients with active schistosomiasis mansoni. The drug was administered, per os, at the dose levels of 2 and $3 \mathrm{mg} / \mathrm{kg} / \mathrm{day}$ with an antacid preparation, twice a day, for 5 consecutive days. In all but 2 patients treatment could be completed. Nausea and/or vomiting, anorexia, vertigo and headache were the commonest side effects. Therapeutic activity was evaluated by repeated stool examinations (4 to 6) and one rectal biopsy performed at least 4 months after treatment. The percentages of patients considered as cured were 83.3 and 80.0 for the schedules of 2 and $3 \mathrm{mg} / \mathrm{kg}$, respectively.

Laboratory and clinical data on the antischistosomal activity of Hycanthone obtained so far emphasize need for further clinical trials with this compound. 


\section{BIBLIOGRAFIA}

1. BERBERIAN, D. A. \& FREELE, H. Chemotherapeutic effect of antischistosomal drugs in experimentally induced Schistosoma mansoni infections in Swiss mice and Syrian Hamsters. J. Parasit. 50: 435-440, 1964.

2. BERBERIAN, D. A. \& FREELE, H. Single dose parenteral therapy of Schistosoma mansoni infection in mice and hamsters with Hycanthone. 41st Annual Meeting Am. Soc. Parasit. San Juan. Abstracts, p. 49, 1966.

3. BLAGG, W., SCHLEDEGEL, E. L., MANSOUR, N. S. \& KHALAF, G. F. A new concentration technic for the demonstration of protozoa and helminth eggs in feces. Am. J. Trop. Med. \& Hyg., 4: 23-28, 1955.

4. CUNHA, A. S., CANÇADO. J. R., PELLEGRINO, J . \& OLIVEIRA, C. A. Valor do oograma para a seleção e avaliação de medicamentos na esquistossomose mansoni. Rev. Inst. Med. trop. São Paulo 5: 75-84, 1963.

5. DIAS, C. B. - Quimioterapia Antimonial na Esquistossomose Mansônica. Belo Horizonte, Tese, 209 pp., 1949.

6. KATZ, N., BITTENCOURT, D., OLIVEIRA, C. A., DIAS, R. P., FERREIRA H., GRINBAUM, E., DIAS, C. B. \& PELLEGRINO, J. - Clinical trials with CIBA 32,644-Ba (Ambilhar) in schistosomiasis mansoni. Fôlha Méd., 53: 561-567, 1966 .

7. KATZ, N., PELLEGRINO, J., FERREIRA, M. T., OLIVEIRA C. A. \& DIAS, C. B. Preliminary clinical trials with Hycanthone, a new antischistosomal agent. Bull. World Health Org, 1967. Em publ.

8. LAMBERT, C. R., IMHOF, P. R. \& ATTAR, H. J. Modifications du tracé électrocardiographique (ECG) sous l'influence du traitement au nitrothiazolylimidazolidinone (CIBA 32,644-Ba). Acta Tropica, 9: 269-274, 1965.

9. OLIVIER, L. \& STIREWALT, M. A. An efficient method for exposure of mice to cercariae of Schistosoma mansoni. J. Parasit., 38: 19-23, 1952.

10. PELlegrino, J. \& SIQUEIRA, A. F. Técnica de perfusão para colheita de
Schistosoma mansoni em cobaias expementalmente infestadas. Rev. Brasil. Malariol. \& Doenças Trop., 8: 589-598, 1956.

11. PELLEGRINO, J., OLIVEIRA, C. A., FARIA, J. \& CUNHA, A. S. New approach to the screening of drugs in experimental schistosomiasis mansoni in mice. Am. J. Trop. Med. \& Hèg., 11: $201-215,1962$.

12. PELLEGRINO, J. \& FARIA, J. The oogram method for the screening of drugs in schistosomiasis mansoni. Am. J. Trop. Med. \& Hyg., 14: 363-369, 1965.

13. PELLEGRINO, J., KATZ, N., OLIVEIRA, C. A. \& OKABE, K . Rectal biopsy and mucosal curettage in Cebus monkeys experimentally infected with Schistosoma mansoni and Schistosoma japonicum. J. Parasit., 51: 617-621, 1965.

14. PELLEGRINO, J., DE MARIA, M. \& FARIA, J. Infection of the golden hamster with Schistosoma mansoni cercariae through the cheek pouch. J. Parasit., 51: 1015, 1965.

15. PELLEGRINO, J., KATZ, N. \& SCHERRER, J.F. - Oogram studies with Hycanthone $^{R}$, a new antischistosomal agent. J. Parasit., 53: 55-59, 1967.

16. PRATA, A. Biópsia retal na esquistossomose mansoni. Bases e aplicações no diagnóstico e tratamento. Tese. Serviço Nacional de Educação Sanitária. Rio de Janeiro, 197 pp., 1957.

17. RODRIGUES DA SILVA, J. O Miracil $D$ no tratamento da esquistossomose mansônica. Rev. Bras. Med., 9:577581,1952 .

18. ROSI, D., PERUZzOTTI, G., DENNIS, E. W., BERBERIAN, D. A., FREELE, H. \& ARCHER. S. A new, active metabolite of "Miracil D". Nature, 208: 1005-1006, 1965.

19. STERLING-WINTHROP R ESEA R CH INSTITUTE. A Summary of laboratoty data on Hycanthone (Win 24,933-a), a schistosomicidal agent. Rensselaer, New York. 26 pp., 1964.

20. STRUFE, R. Stoffwechsel-Untersuchungen mit Miracil $D$. Medizin $u$. Chemie. 7: 337-366, 1963 